\title{
Responses of Single Cutaneous Fibers to Noxious Thermal Pulse Stimulation of Cat Upper Hind Limb
}

\author{
Chun-yuan $\mathrm{Li}^{1}$, Thomas J. Morrow ${ }^{*}$ and Kenneth L. Casey $*, * *, 2$ \\ * Departments of Physiology and ** Neurology, University of Michigan, and Neurology Research \\ Laboratories (Neurophysiology), Veterans Administration Medical Center, Ann Arbor, MI 48105 (U.S.A.)
}

(Received 12 March 1984, accepted 26 September 1984)

\section{Summary}

Previous experiments have shown that cats respond to noxious thermal pulse stimulation of the upper hind limb at an average latency of $2.3 \mathrm{sec}$. To determine if $\mathrm{C}$ fiber afferents could mediate this response, we recorded the response latency and threshold of single fibers of cat femoral cutaneous nerve to the same stimuli used in the behavioral experiments. Of $28 \mathrm{C}$ fibers tested, $10(36 \%)$ responded to heating; 4 $(17 \%)$ of 24 fibers with conduction velocities of $2.5-30 \mathrm{~m} / \mathrm{sec}$ responded to heat. All fibers but one discharged within $1.0 \mathrm{sec}$ of thermal pulse onset (median: $800 \mathrm{msec}$ ) at an average and median threshold of $46^{\circ} \mathrm{C}$. Thermal nociceptors with $\mathrm{C}$ fiber afferents could mediate the initiation of behavioral nocifensive responses to heat in the cat.

\section{Introduction}

We have recently shown that rapid onset $\left(38-17^{\circ} \mathrm{C} / \mathrm{sec}\right)$ thermal pulses of $47-55^{\circ} \mathrm{C}$, delivered to the shaved upper hind limb of cats, elicits nocifensive responses at an average latency of $2.3 \pm 0.12$ (S.E.) sec from the onset of the stimulus pulse plateau [5]. Most behavioral responses occurred within $2.5 \mathrm{sec}$ and a significant number were elicited between 1 and $2 \mathrm{sec}$. These behavioral reponse latencies raise the question about the type of afferent fiber initiating heat-evoked nocifensive

1 Research Fellow of the World IIealth Organization on leave from The Institule of Acupuncture and Moxibustion, Academy of Traditional Chinese Medicine, Beijing, People's Rep. of China.

2 To whom reprint requests should be addressed: Neurology Service, VA Medical Center, 2215 Fuller Road, Ann Arbor, MI 48105, U.S.A. 
behavior in the cat. The high threshold heat receptors with afferent $C$ fibers would seem to be likely candidates for this role. However, Iggo [12] reported a latency of $1.2 \mathrm{sec}$ for a heat nociceptive $\mathrm{C}$ fiber afferent in the cat saphenous nerve, and Beck et al. [1] found that $C$ fiber heat responses in the plantar nerves were delayed for $2 \mathrm{sec}$ or longer, possibly due to the slow thermal conduction in the cat's footpad. The experiments of Martin and Manning [14] and of $\mathrm{Hu}$ et al. [11] raised the additional possibility that $A \delta$ heat nociceptors, like those found in primate skin [6], might be exclusively responsible for initiating the fast heat-evoked nocifensive responses in the cat.

We used the collision of $\mathrm{C}$ and $\mathrm{A} \delta$ compound action potentials with thermally evoked activity from the cat's skin to estimate the threshold, latency and composition of the afferent response to a noxious thermal pulse [5]. The results suggested strongly that $\mathrm{C}$ afferents mediated the nocifensive behaviors. However, the compound action potential collision method is a relatively low resolution technique, and the conclusions derived from its use should be tested by single fiber analysis. Accordingly, we have tested a small sample of thermally responsive single cutaneous fibers in the cat upper hind limb to determine if the threshold and latency of their response are consistent with the mediation of short latency nocifensive behaviors.

\section{Methods}

Twenty-one adult cats of both sexes were used for these experiments. Each cat was anesthetized with pentobarbital $(50 \mathrm{mg} / \mathrm{kg}$ i.v.), paralyzed with gallamine triethiodide and placed on a respirator at ventilatory parameters sufficient to maintain expired $\mathrm{CO}_{2}$ at approximately $4 \%$. Rectal temperature was maintained at $37-38^{\circ} \mathrm{C}$. Supplementary anesthetic, gallamine and $5 \%$ dextrose in water were administered via an indwelling intravenous catheter.

Branches of the lateral or posterior femoral cutaneous nerves were exposed at the hip for approximately $5 \mathrm{~cm}$. Single fibers were dissected under the microscope from fine multifiber strands cut proximally and placed on a black plastic plate immersed in warm mineral oil. Mechanical stimuli were applied periodically to identify the receptive fields of multifiber strands and single fibers. After testing for thermal responses, fine cutaneous needle electrodes were used to deliver single shocks $(1-15$ $\mathrm{mA}, 1-2 \mathrm{msec})$ to the receptive field to determine conduction latency. Conduction velocity was calculated from the conduction distance.

Action potentials were recorded with fine platinum wire electrodes and conventional AC coupled amplifiers with outputs to a storage oscilloscope and a window amplitude discriminator. One channel of a digital thermal chart recorder received the pulse output of the discriminator. The output of a thermocouple amplifier was led into a second channel for recording heat pulses.

Thermal pulse stimuli were delivered to the shaved skin of the lateral thigh with a spring-loaded, water-cooled contact thermode of the type previously described [16] and used in behavioral studies [5]. Stimulus temperature measurement and control were obtained via a thermocouple at the skin-thermode interface. Glycerine was 
applied to the skin to facilitate thermal conduction. Thermal pulses were delivered on a $38^{\circ} \mathrm{C}$ adapting temperature and had a rising phase of $14^{\circ} \mathrm{C} / \mathrm{sec}$. Total pulse duration was approximately $12 \mathrm{sec}$ with a maximum plateau duration of $9 \mathrm{sec}$. To avoid tissue damage and minimize receptor sensitization or desensitization, only 3 intensity levels were tested $\left(43,50\right.$ and $\left.53^{\circ} \mathrm{C}\right)$ in ascending order with at least $3 \mathrm{~min}$ intervals between trials. The response latency and threshold of each fiber were estimated by measuring the temperature at the time of the first spike following the onset of pulses that elicited increased spike activity. When more than one of the test pulses evoked a response, the average latency and threshold were used as the estimate.

\section{Results}

Recordings were taken from a total of 83 single fibers, 59 of which were tested for responses to thermal stimulation. A histogram of the distribution of the conduction velocities of the recorded fibers is shown in Fig. 1. The dissection and thermal testing was intentionally biased in favor of smaller diameter fibers because we wished to limit skin exposure to noxious thermal stimuli by testing fibers that were most likely to respond to such stimuli. As shown in Fig. 1, the highest proportion of thermally responsive fibers is found among those with conduction velocities in the range of $C$ fibers (36\%) and the smaller diameter A $\delta$ fibers (27\%). Only 4 (17\%) of 24 tested fibers with conduction velocities in the range of $A \delta$ afferents $(5-30 \mathrm{~m} / \mathrm{sec})$ responded to heat.
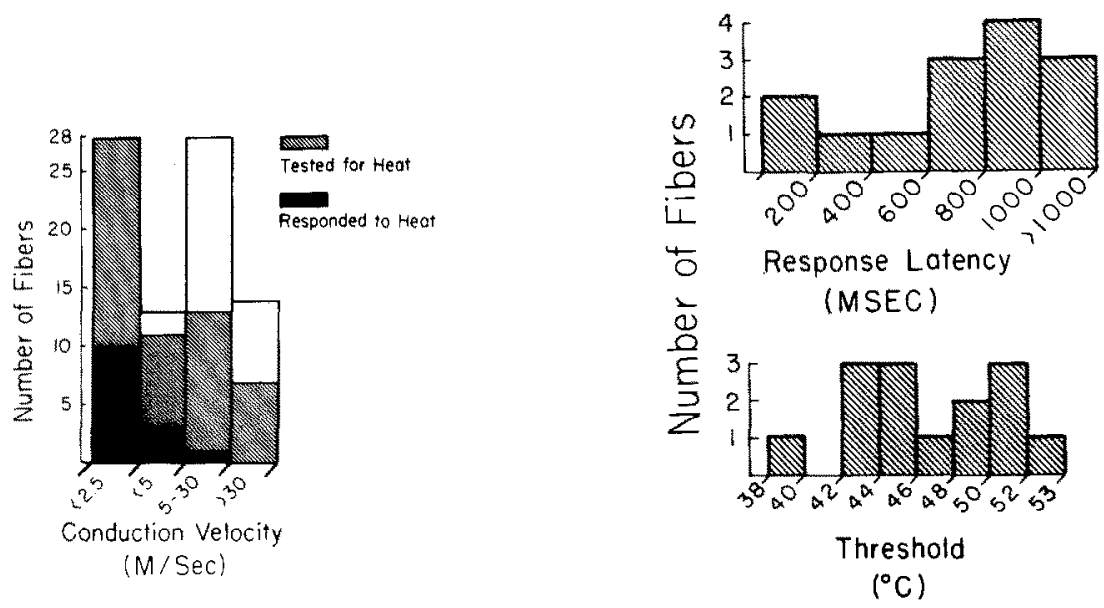

Fig. 1. Distribution of conduction velocities of all fibers recorded, tested with heat pulses, and responsive to heating.

Fig. 2. Distribution of response latencies and thresholds of all fibers responding to heat pulses. 
All but one of the 14 heat-responsive fibers were activated within $1 \mathrm{sec}$ of the onset of the thermal pulse. The single exception was the fiber with the highest threshold $\left(52^{\circ} \mathrm{C}\right)$ and latency of $2 \mathrm{sec}$. Fig. 2 shows the distribution of latencies and thermal response thresholds. The average latency was $745 \pm 125$ (S.E.) msec (median $=800 \mathrm{msec}$ ) and the average thermal response threshold was $46.2 \pm 1.0$ (S.E.) ${ }^{\circ} \mathrm{C}$ (median $=46^{\circ} \mathrm{C}$ ). There was no relationship between conduction velocity and thermal theshold or latency in this small sample of fibers. The conduction velocities of fibers with thresholds above $48^{\circ} \mathrm{C}$ ranged from 2.3 to $0.4 \mathrm{~m} / \mathrm{sec}$ and those with lower thresholds had conduction velocities of $3.1-0.4 \mathrm{~m} / \mathrm{sec}$ with the exception of one fiber with a conduction velocity of $20 \mathrm{~m} / \mathrm{sec}$ (threshold, $43^{\circ} \mathrm{C}$; latency, 150 $\mathrm{msec})$. The average conduction velocity of all thermally responsive fibers was $2.9 \pm 1.3$ (S.E.) $\mathrm{m} / \mathrm{sec}$ (median $=1.8 \mathrm{~m} / \mathrm{sec}$ ).

With the exception of a few fibers that discharged in the absence of experimentally induced stimulation (see below), all fibers were identified by their responses to mechanical stimuli applied within the receptive field. Since we wished to avoid noxious mechanical or thermal stimuli that could induce sensitization or suppression of response, we could not have identified fibers responding exclusively to such stimuli. The adequate mechanical stimulus ranged from light touching of the shaved skin to firm but innocuous pressure or rubbing.

All heat-responsive fibers showed increasing responses to increases in thermal pulse amplitude within the noxious range. Fig. 3 shows a typical example of the stimulus-response relationship. This fiber, like approximately two-thirds of our sample population, was inactive in the absence of stimulation. A few spikes were discharged during the $43^{\circ} \mathrm{C}$ trial but a clear response, suitable for latency and threshold estimation, was obtained only with the 50 and $53^{\circ} \mathrm{C}$ trials, each of which

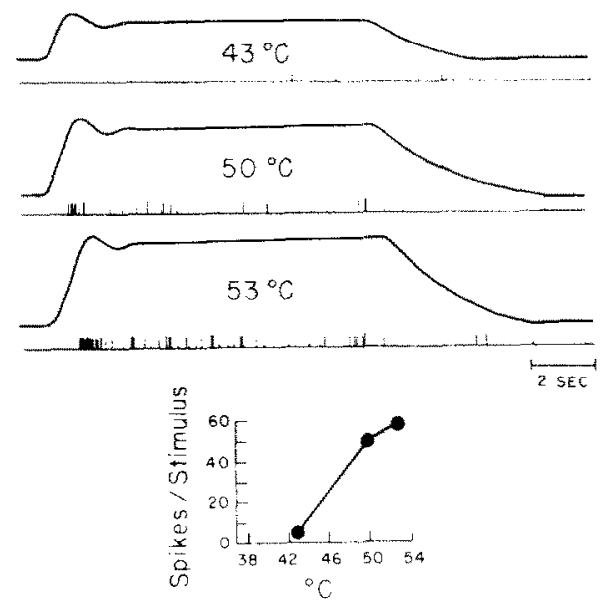

Fig. 3. Sample records of a $\mathrm{C}$ fiber (conduction velocity: $0.6 \mathrm{~m} / \mathrm{sec}$ ) discharging when the pulse temperature reaches $49^{\circ} \mathrm{C}$ at a latency of $900 \mathrm{msec}$. Stimulus-response curve for this fiber is shown below sample records. 
elicited an initial burst of spikes followed by a decelerating discharge for the duration of the stimulus. Five fibers showed a slightly different response as illustrated in Fig. 4. A low level of prestimulus activity (approximately $0.1 \mathrm{~Hz}$ ) was increased during the $43^{\circ} \mathrm{C}$ trial. Stimuli in the noxious range, however, evoked more definite and increasingly intense responses that continued for 5-8 sec beyond the end of the stimulus. The fibers showing this afterdischarge response had no additional characteristics that distinguished them from other fibers in our sample.

We made no effort to induce or study sensitization and desensitization of thermal nociceptors $[1,2,9]$. In fact, we used a limited number of short duration trials delivered at 3-5 min intervals in an effort to avoid such phenomena and obtain reliable threshold and latency measurements. This approach was apparently successful because there was close agreement between the measurements made on the 50 and $53^{\circ} \mathrm{C}$ trials.

Although we made no systematic effort to study cooling responses or suppression

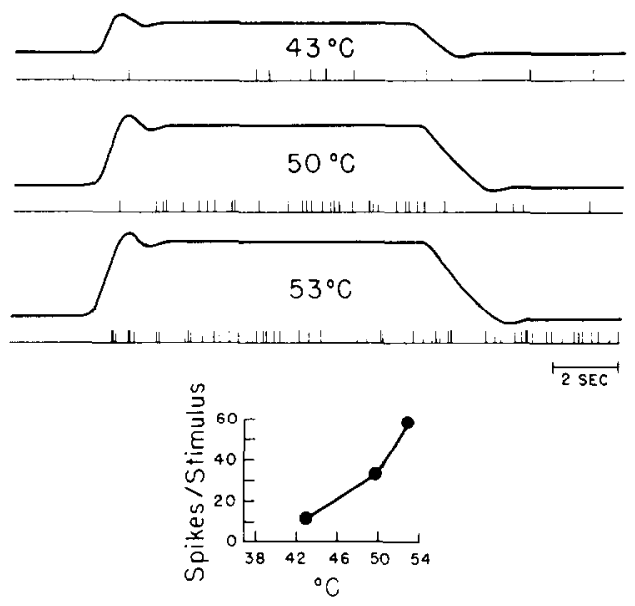

Fig. 4. Sample records of a C fiber (conduction velocity $2.1 \mathrm{~m} / \mathrm{sec}$ ) discharging when the pulse temperature reaches $49^{\circ} \mathrm{C}$ at a latency of $850 \mathrm{msec}$. Stimulus-response curve for this fiber is constructed for the duration of the stimulus only and does not include the period of afterdischarge shown in the recording.

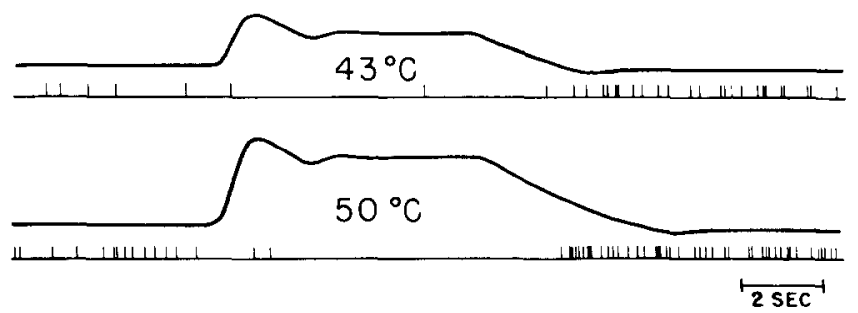

Fig. 5. Fiber with conduction velocity of $2.6 \mathrm{~m} / \mathrm{sec}$ showing suppressed activity during noxious and innocuous thermal pulses. Note increased activity during cooling phase of each thcrmal pulse. 
of activity by heat pulses, we found 13 fibers that were slightly active at the adapting temperature, showed increased activity when the stimulating thermode was cooled to $25^{\circ} \mathrm{C}$ and decreased activity during heat pulses. Four of these fibers had conduction velocities above $30 \mathrm{~m} / \mathrm{sec}, 4$ between 5 and $30 \mathrm{~m} / \mathrm{sec}, 2$ between 2.5 and $5 \mathrm{~m} / \mathrm{sec}$ and 3 below $2.5 \mathrm{~m} / \mathrm{sec}$. Four of the slowest conducting of these fibers displayed an off-response following heat pulses as illustrated in Fig. 5. The prestimulus activity was suppressed during an innocuous heat pulse and slightly increased following the stimulus. The slightly increased activity persisted for $2 \mathrm{~min}$ and was again decreased during the subsequent $50^{\circ} \mathrm{C}$ trial. Fiber discharge then further increased during the cooling phase of the thermal pulse and persisted for at least $2 \mathrm{~min}$ thereafter. The effect of more intense stimuli was not tested.

\section{Discussion}

The results of this single fiber study are in accord with those obtained by colliding heat-evoked activity with an antidromic $\mathrm{C}$ fiber compound action potential [5]. That experiment indicated that thermal pulses of the type used in this experiment evoked activity in a population of $\mathrm{C}$ fibers at latencies of $570 \mathrm{msec}$ and at a temperature of approximately $46^{\circ} \mathrm{C}$. The longer average and median latency obtained in the present set of experiments may be attributed to our ability to detect the longer latency responses that could not be detected by lower resolution population recordings.

Nearly all the fibers with conduction velocities less than $2.5 \mathrm{~m} / \mathrm{sec}$ are likely to be unmyelinated $\mathrm{C}$ afferents. It is possible that electrical stimulation of the skin could lead to an underestimate of conduction velocity if the unmyelinated terminal ending of an $A \delta$ fiber contributed significantly to the conduction time. However, at our usual conduction distance of $60-70 \mathrm{~mm}$, an added $6-7 \mathrm{msec}$ would be necessary to produce an apparent conduction velocity of $2.0 \mathrm{~m} / \mathrm{sec}$ for an $A \delta$ fiber conducting impulses at $2.5 \mathrm{~m} / \mathrm{sec}$. Only two fibers had conduction velocities between 2.0 and $2.5 \mathrm{~m} / \mathrm{sec}$; those with slower conduction velocities ranged between 1.8 and 0.4 $\mathrm{m} / \mathrm{sec}$. Since the observations of Kruger et al. [13] show that finely myelinated fibers are present up to the papillary layer of the dermis of hairy cat skin, it is unlikely that our intracutaneous needle electrodes stimulated unmyelinated endings of sufficient length to result in a significant misclassification of fiber type based on conduction velocity. Furthermore, Menétrey et al. [15] found that transcutaneous and direct nerve stimulation of $\mathrm{C}$ fibers activated rat dorsal horn cells at similar latencies.

The response latency and threshold of heat nociceptors with $\mathrm{C}$ fibers are also consistent with the hypothesis that these afferents mediate the initiation of the nocifensive behavioral responses of the cat to noxious thermal stimulation of the upper hind limb. Using the same thermode, thermal pulse amplitudes, and thermal pulse onset slopes ranging from 38 to $17^{\circ} \mathrm{C} / \mathrm{sec}$, it was found that cats emitted nocifensive responses at an average latency of $2.3 \pm 0.12$ (S.E.) sec from the onset of the pulse plateau [5]. The average response threshold for different behaviors ranged between 47 and $55^{\circ} \mathrm{C}$. The present results show that $\mathrm{C}$ fiber heat nociceptors respond at latencies and thermal thresholds consistent with the initiation of these 
behaviors. Since these receptors are activated before the first second of the onset of the thermal pulse, the activity in afferents conducting at an average velocity of 1.0 $\mathrm{m} / \mathrm{sec}$ would travel the estimated $90 \mathrm{~mm}$ from the stimulus site to arrive at the spinal cord well within the first second of the thermal pulse plateau. This determination, based on the present results, resolves the issue raised by the long latency $\mathrm{C}$ fiber heat responses to stimulation of the cat footpad recorded by Beck et al. [1]. As they suggested, the delayed responses they obtained were probably attributable to the thermal insulating effect of the cornified footpad skin and adjacent hair. Our behavioral and neurophysiological experiments were conducted on the much thinner shaved skin of the upper hind limb. This may also account for the agreement between our latency measurements and the observations of Iggo [12] on the heat responses of a $\mathrm{C}$ fiber of cat saphenous nerve.

We would not have tested fibers unresponsive to mechanical stimuli because we did not use electrical stimulation of the nerve as a search stimulus. Limiting our heat pulses to $53^{\circ} \mathrm{C}$ may also reduce the number of heat-sensitive fibers we could find. Taking this into account, the proportion of $\mathrm{C}$ fibers responding to heat stimuli in our sample ( $36 \%$ of 28 fibers) is comparable to that reported by Beck et al. [1] (44\% of 59 fibers) and Bessou and Perl [3] (45\% of 86 fibers) for C fibers responding to mechanical stimulation of cat skin. However, in a recent study of nociceptive $\mathrm{C}$ fiber afferents in the rat, Fleischer et al. [9] found that, of the $\mathrm{C}$ fibers responsive to mechanical stimuli, $65 \%$ of 83 saphenous fibers and $94 \%$ of 97 coccygeal nerve fibers were responsive to heat. These differences probably reflect differences between species and the functional specialization of different cutaneous nerves.

The smaller proportion of heat-responsive A $\delta$ fibers $(17 \%)$ is in agreement with the data of Fitzgerald and Lynn [8], who found that, in rabbit and cat, only $6(11 \%)$ of 55 unsensitized high threshold mechanoreceptors with myelinated afferent fibers responded to an initial noxious heat pulse. While these fibers may contribute to the initiation of feline nocifensive responses, the present results indicate that they may not play an exclusive or predominant role in this function.

The fibers with decreased activity during heat pulses and increased activity during cooling may be a mixture of mechanoreceptive and thermoreceptive afferents that are known to show such responses to innocuous changes in skin temperature in the cat $[3,4,7,10]$. The $\mathrm{C}$ fibers we recorded did not appear to have the properties described for high threshold cold afferents in cat [12] or rat [9]. Since these fibers responded with increasing discharges during the cooling phase of noxious heat pulses, their activity cannot contribute to the initiation of nocifensive responses. These afferents may, however, trigger some of the longer latency responses to noxious thermal pulses [5].

\section{Acknowledgements}

The technical assistance of Avery Gottfried is gratefully acknowledged.

This study was supported by the National Institute of Neurological and Communicative Disorders and Stroke Grant NS 12015, and by the Veterans Administration. 


\section{References}

1 Beck, P.W., Handwerker, H.O. and Zimmermann, M., Nervous outflow from the cat's foot during noxious radiant heat stimulation. Brain Res., 67 (1974) 373-386.

2 Beitel, R.E. and Dubner, R., Response of unmyelinated (C) polymodal nociceptors to thermal stimuli applied to monkey's face, J. Neurophysiol., 39 (1976) 1160-1175.

3 Bessou, P. and Perl, E.R., Response of cutaneous sensory units with unmyelinated fibers to noxious stimuli. J. Neurophysiol., 32 (1969) 1025-1043.

4 Burgess, P.R., Petit, D. and Warren, R.M., Receptor types in cat hairy skin supplied by myelinated fibers, J. Neurophysiol., 31 (1968) 833-848.

5 Casey, K.L. and Morrow, T.J., Nocifensive responses to cutaneous thermal stimuli in the cat: stimulus-response profiles, latencies, and afferent activity, J. Neurophysiol., 50 (1983) 1497-1515.

6 Dubner, R., Price, D.D., Beitel, R.E and Hu, J.W., Peripheral neural correlates of behavior in monkey and human related to sensory-discriminative aspects of pain. In: D.J. Anderson and B. Matthews (Eds.), Pain in the Trigeminal Region, Elsevier/North-Holland Biomedical Press, Amsterdam, 1977. pp. $57-66$

7 Duclaux, R., Schaefer, K. and Hensel, H., Response of cold receptors to low skin temperatures in nose of the cat, J. Neurophysiol.. 43 (1980) 1571-1577.

8 Fitzgerald, M. and Lynn, B. The sensitization of high threshold mechanoreceptors with myelinated axons by repeated heating, J. Physiol. (Lond.), 365 (1977) 549-563.

9 Fleischer, E., Handwerker, H.O. and Joukhadar, S., Unmyelinated nociceptive units in two skin areas of the rat, Brain Res., 267 (1983) 81-92.

10 Hensel, H., Iggo, A. and Witt, I., A quantitative study of sensitive cutaneous thermoreceptors with C afferent fibres, J. Physiol. (Lond.), 153 (1960) 113-126.

$11 \mathrm{Hu}$, J.W. Dostrovsky, J.O. and Sessle, B.J., Functional properties of neurons in cat trigeminal subnucleus caudalis (medullary dorsal horn). I. Responses to oral-facial noxious and nonnoxious stimuli and projections to thalamus and subnucleus oralis, J. Neurophysiol., 45 (1981) 173-192.

12 Iggo, A., Cutaneous heat and cold receptors with slowly conducting (C) afferent fibres, Quart. J. exp. Physiol., 44 (1959) 362-370.

13 Kruger, L., Perl, E.R. and Sedivec, M.J., The structure of myelinated mechanical nociceptor endings in cat hairy skin, J. comp. Neurol. 198 (1981) 137154.

14 Martin, III, H.F. and Manning, J.W., Rapid thermal cutaneous stimulation: peripheral nerve responses, Brain Res., 16 (1969) 524-526.

15 Menétrey, D., Giesler, G.J. and Besson. J.M., An analysis of response properties of spinal cord dorsal horn neurones to nonnoxious and noxious stimuli in the spinal rat, Exp. Brain Res., 27 (1977) 15-33.

16 Morrow, T.J. and Casey, K.L., A contact thermal stimulator for neurobehavioral research on temperature sensation, Brain Res. Bull., 6 (1981) 281-284. 